\title{
ANALISIS ARCHITECTURE TEKNOLOGI UNTUK MENINGKATKAN LAYANAN RUMAH SAKIT DENGAN MENGGUNAKAN TOGAF ADM
}

\author{
Nyoman Ayu Nila Dewi ${ }^{1)}$ I Nyoman Yudi Anggara Wijaya ${ }^{2)}$ \\ Prodi Sistem Informasi 1) 2) \\ STMIK STIKOM Bali ${ }^{1)}$ STMIK PRIMAKARA ${ }^{2)}$ Denpasar, Bali \\ ayu.nila8@yahoo.co.id ${ }^{1)}$ inyomanyudi@gmail.com ${ }^{2)}$
}

\begin{abstract}
Making a plan is needed by all private companies and government agencies, planning by combining a technology in each process is something that is needed by the company. Current technological competition causes many companies to compete to be able to utilize technology that can help existing business processes. The business process that really needs a technology is a hospital, now the hospital is one of the institutions that have quite complex business processes, ranging from inpatient and outpatient admissions to the payment process. Problems that can be seen today where people can choose hospitals with good service. Many people are competing to be able to get a good, friendly and fast service when using hospital facilities. The problems that arise at this time are many private and state hospitals still experiencing problems when collecting patient medical records, a phenomenon that occurs where people will move around the hospital to get good service and get an easy process. Of the problems that occur with the data collection of patients' medical records that until now have not been able to be integrated with hospitals. Technology is needed to solve current problems. The use of technology in integrating business processes is needed to be able to compete with similar companies. Seeing this, a strategic planning to improve hospital services is needed by using the TOGAF ADM framework. The results of this study will provide an overview of technology analysis and centralized recording data planning by producing a framework and analysis of technology to improve technology and integrate business processes with existing technologies.
\end{abstract}

Keyword : Planning, Systems, TOGAF ADM, Hospital, Technology

\begin{abstract}
Abstrak
Pembuatan sebuah perencanaan sangatlah dibutuhkan oleh semua perusahaan swasta maupun instansi pemerintahan, perencanaan dengan menggabungkan sebuah teknologi dalam setiap proses merupakan hal yang sangat dibutuhkan oleh perusahaan. Persaingan teknologi saat ini menyebabkan banyak perusahaan berlomba-lomba untuk dapat memanfaatkan teknologi yang dapat membantu proses bisnis yang ada. Proses bisnis yang sangat membutuhkan sebuah teknologi adalah Rumah sakit, saat ini rumah sakit merupakan salah satu instansi yang memiliki proses bisnis yang cukup kompleks, mulai dari penerimaan pasien rawat inap maupun rawat jalan sampai dengan proses pembayaran. Permasalahan yang dapat dilihat saat ini dimana masyarakat dapat memilih rumah sakit dengan pelayanan yang baik. Banyak masyarakat berlomba-lomba untuk bisa mendapatkan sebuah pelayanan yang baik, ramah dan cepat saat menggunkana fasilitas rumah sakit. Permasalahan yang muncul saat ini banyaknya rumah sakit swasta maupun negri masih mengalami kendala pada saat pendataan rekam medis pasien, fenomena yang terjadi dimana masyarakat akan berpindah-pindah rumah sakit untuk mendapatkan pelayanan yang baik dan mendapatkan proses yang mudah. Dari permasalahan yang terjadi dengan pendataan rekam medis pasien yang sampai saat ini belum dapat terintegrasi dengan rumah sakit. Teknologi sangat dibutuhkan untuk menyelesaikan permasalahan yang ada saat ini. Pemanfaatan teknologi dalam mengintegrasikan proses bisnis dibutuhkan untuk dapat bersaing dengan perusahaan sejenis. Melihat hal tersebut maka dibutuhkan suatu perencanaan strategis peningkatan pelayanaan rumah
\end{abstract}


sakit dengan menggunakan framework TOGAF ADM. Hasil dari penelitian ini akan memberikan gambaran analisis teknologi dan perencanaan pendataan rekamedis terpusat dengan menghasilkan suatu kerangka kerja dan analisis teknologi untuk meningkatkan teknologi dan mengintegrasikan proses bisnis dengan teknologi yang ada saat ini.

Kata kunci: Perencanaan, Sistem, TOGAF ADM, Rumah Sakit, Teknologi

\section{PENDAHULUAN}

Rekam medis adalah salah satu data yang sangat penting dan rahasia untuk diketahui oleh masyarakat luas, dalam hal ini rekam medis pasien hanya tersimpan di rumah sakit dan diolah oleh pihak rumahsakit untuk digunakan datanya. Rumah sakit merupakan salah satu instansi pemerintahaan yang memiliki proses bisnis yang cukup kompleks mulai dari penerimaan pasien sampai dengan pembayaran pasien setelah melakukan perawatan. Pengelompokan pasien dibagi menjadi 2 kelompk yaitu pasien rawat inap dan pasien rawat jalan dengan proses yang berbeda-beda. Persaingan antar rumah sakit menjadi permasalahan yang ada saat ini dimana banyak rumah sakit berlomba-lomba untuk memberikan pelayanan yang baik, cepat dan ramah kepada pasien. Seluruh proses bisnis yang ada dalam rumah sakit dapat diintegrasikan dengan teknologi. Pengintegrasian teknologi dalam merencanakan pelayanan yang baik membutuhkan suatu perencanaan yang terarah dan baik. Dalam permasalahan ini akan mengimplementasikan framework TOGAF ADM untuk memberikan kerangka kerja dalam peningkatan pelayanan rumah sakit.

Permasalahan yang muncul saat ini adalah masyarakat berlomba-lomba untuk memilih rumah sakit yang memberikan pelayanan yang baik dan cepat untuk mendapatkan pelayanan medis yang baik. Banyak masyarakat mulai berpindah dari rumah sakit 1 ke rumah sakit lainnya untuk mendapatkan pelayanan yang baik. Hal ini menjadi permasalahan rumah sakit dimana persaingan antar rumah sakit menjadi masalah yang cukup berdampak terhadap keberlangsungan proses bisnis tersebut. Pelayanaan yang dapat dilihat saat ini adalah pendataan rekam medis pasien rawat inap maupun pasien rawat jalan. Pendataan yang baik dan terintegrasi dengan rumah sakit lainnya menjadi solusi yang sangat dibutuhkan oleh masyarakat. Pengintegrasian data rekam medis pasien dapat memudahkan pasien untuk melakukan pemeriksaan di salah satu rumah sakit tanpa harus mendata kembali rekam medis pasien. Solusi yang dapat dibangun dari permasalahan ini adalah mengintegrasikan IT dengan proses bisnis dimana data rekam medis akan terpusat pada 1 rumah sakit pusat dan riwayat pasien tersebut dapat terbaca oleh seluruh rumah sakit yang telah terintegrasi dengan rumah sakit pusat. Dalam pengimplementasian tersebut dibutuhkan suatu framework yang dapat memberikan kerangka kerja yang terarah. Dalam penelitian ini akan menggunakan TOGAF ADM untuk proses analisa agar dapat memberikan gambaran kerangka kerja dalam perencanaan layanan teknologi yang terintegrasi dengan proses bisnis.

Hasil penelitian ini akan memberikan dokumentasi blueprint atau kerangka kerja dalam meningkatkan pelayanan rumah sakit. Tujuan dari penelitian ini diharapkan dapat memberikan peningkatan pelayanan dalam integrasi denganrumah sakit lainnya dan memudahkan pasien dalam melakukan pemeriksanaan kesehatan. Rumusan masalah yang dapat diangkat dari latar belakang diatas adalah, bagaimana mengimplementasikan framework TOGAF ADM dalam meningkatkan pelayanan di rumah sakit.

\section{LANDASAN TEORI}

The Open Group Architecture Framework (TOGAF)

TOGAF merupakan sebuah framework untuk mengembangkan arsitektur perusahaan. TOGAF memiliki metode yang detail sekaligus tools pendukung untuk mengimplementasikannya. Kerangka kerja ini dikeluarkan oleh The Open Groupees 
Architecture Framework pada tahun 1995. Berikut ini adalah struktur dan komponen dari TOGAF (The Open Group, 2011):

\section{Architecture Development Method (ADM)}

Architecture Development Method (ADM) merupakan inti dari TOGAF sebagai hasil kontribusi dari banyak praktisi arsitektur teknologi informasi di dunia. Secara spesifik ADM dirancang untuk memenuhi kebutuhan bisnis dan teknologi informasi berskala enterprise. ADM dilengkapi dengan banyak alat bantu (tools) baik dalam perencanaan maupun prosesnya, antara lain:

1. Satu set arsitektur view yang mencakup view bisnis, data, aplikasi, dan teknologi.

2. Satu set deliverables yang direkomendasikan.

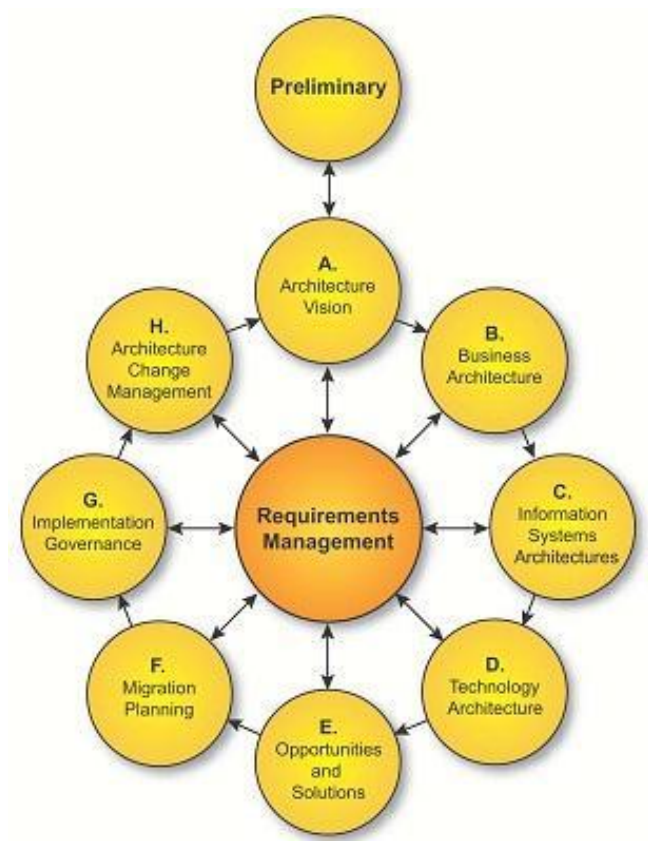

Gambar 1. Architecture Development Method (ADM)

Tahapan-tahapan kerangka kerja pada Gambar 1 diatas dapat dijelaskan sebagai berikut:

\section{A. Preliminary Phase: Framework and Principles}

Tahapan ini bertujuan untuk menentukan ruang lingkup, kerangka kerja dan metode yang akan digunakan untuk mengembangan rancangan arsitektur. Input pada tahapan ini berisi referensi kerangka kerja, input non-arsitektur dan input arsitektur. Dalam tahap ini juga merupakan tahap persiapan dalam proses perancangan, penyusunan framework dan prinsip-prinsip arsitektur. Framework diuraikan dalam bentuk visi arsitektur, sedangkan prinsipprinsip diuraikan untuk masing-masing arsitektur yang akan dikaji yaitu dalam proses bisnis, aplikasi, data dan teknologi.

\section{B. Phase A: Architecture Vision}

Tahap ini menggambarkan batasan-batasan dari rancangan arsitektur dan bertujuan untuk mengembangkan gambaran rancangan arsitektur yang dapat diterapkan berdasarkan prinsip-prinsip arsitektur. Pada tahap ini dilakukan pendefinisian

ruang lingkup, batasan-batasan dan ekspektasi dari rancangan arsitektur, yang kemudian ditetapkan visi arsitektur yang diusulkan. Konteks bisnis divalidasi untuk menyusun statement of architecture work.

\section{Phase B: Business Architecture}

Mendeskripsikan arsitektur bisnis saat ini, sasaran, dan menentukan gap diantara arsitektur bisnis. Pada fase ini dilakukan pendefinisian kondisi awal arsitektur bisnis. Pada fase ini juga dilakukan pemodelan bisnis dengan memilih tool yang tepat untuk menggambarkan arsitektur bisnis. Pemodelan arsitektur bisnis dilakukan dengan mengidentifikasikan area fungsional utama, menetapkan fungsi bisnis, dan area fungsionalitas pendukung.

\section{Phase C: Information Systems Architectures}

Pada fase ini ditekankan bagaimana arsitektur sistem informasi dibangun, yang meliputi arsitektur data dan arsitektur aplikasi yang akan digunakan oleh organisasi. Arsitektur data melakukan indentifikasi entitas data, serta menggambarkan asosiasi data dengan proses dan skema data. Indentifikasi entitas data dilakukan berdasarkan arsitektur bisnis yang ada. Aliran informasi antar sistem didekomposisikan sebagai entitas data. Pada arsitektur data, juga dilakukan dengan mengidentifikasi seluruh komponen data yang akan digunakan oleh aplikasi untuk menghasilkan informasi yang dibutuhkan organisasi berdasarkan kebutuhan area fungsional bisnis yang telah ditetapkan. 
Identifikasi yang dilakukan adalah menentukan kandidat entitas data, mendefinisikan entitas data, dan membuat relasi antara fungsi bisnis dan entitas data. Teknik yang bisa digunakan adalah ER-Diagram, class diagram, dan object diagram Pada arsitektur aplikasi, dilakukan dengan mengidentifikasi kandidat aplikasi, menentukan jenis aplikasi yang dibutuhkan untuk memproses data dan mendukung bisnis, serta membuat pemodelan arsitektur aplikasi.

\section{E. Phase D: Technology Architecture}

Pada fase ini didefinisikan kebutuhan teknologi untuk mengolah data. Langkah awal yang dilakukan adalah menentukan kandidat teknologi yang akan digunakan untuk menghasilkan pemilihan teknologi dan platform teknologi yang ada dalam aplikasi, meliputi perangkat lunak dan perangkat keras. Teknik yang digunakan adalah dengan mengidentifikasikan prinsip platform teknologi. Sasaran dari tahapan ini adalah untuk membangun arsitektur teknologi yang akan dijadikan dasar pada saat implementasi. Pengembangan arsitektur teknologi ini dilakukan melalui 3 tahap, yaitu identifikasi arsitektur baseline (as is), menetukan target (tobe) arsitektur,

dan melakukan gap analysis antara baseline dengan target.

\section{F. Phase E: Opportunities and Solutions}

Pada fase ini ditekankan manfaat yang diperoleh dari arsitektur enterprise. Dilakukan evaluasi gap dari arsitektur enterprise yang meliputi arsitektur bisnis, data, arsitektur aplikasi, dan arsitektur teknologi untuk selanjutnya membuat strategi untuk solusi. Hasil dari fase ini merupakan dasar dari rencana implementasi yang diperlukan untuk mencapai sasaran rancangan arsiterktur.

\section{G. Phase F: Migration Planning}

Tahap ini bertujuan untuk membuat suatu rencana migrasi, termasuk prioritas pekerjaan. Sasaran dari tahap ini adalah, memilah beberapa proyek-proyek implementasi berdasarkan prioritas utama.
Pada tahap ini roadmap dari keseluruhan implementasi disusun.

\section{H. Phase G: Implementation Governance}

Tahapan ini bertujuan untuk menyusun suatu tata laksana implementasi, termasuk menyusun dan memformalisasi tim, menyusun manajemen proyek, membuat suatu manajemen komunikasi dari proyek tersebut, dll.

\section{Phase H: Architecture Change Management}

Tahapan ini merupakan tahapan penting dari metodologi TOGAF karena infrastruktur TI akan terus berkembang menyesuaikan dengan kebutuhan bisnis yang ada. Sasaran dari tahapan ini adalah membangun suatu arsitektur proses manajemen perubahan bagi dasar arsitektur yang baru yang mana dilakukan setelah tahapan tata laksana implementasi dilaksanakan. Dari seluruh tahapan ADM, terdapat banyak deriverables yang dihasilkan, baik sebagai input maupun output. Namun demikian, deliverables tersebut adalah rekomendasi, bukan dimaksudkan untuk diikuti secara lengkap. Jumlah deliverables tersebut bisa disesuaikan dengan ruang lingkup yang sudah didefinisikan.

\section{PEMBAHASAN SISTEM}

Pada bagian ini akan membahas data yang dianalisis untuk dapat digambarkan kedalam kerangka kerja, model analisis data yang digunakan yaitu TOGAF ADM. Tahapan awal sebelum melakukan analisa dengan TOGAF ADM adalah langkah persiapan yaitu preliminary phase dengan bertujuan untuk menentukan kemampuan arsitektur yang diinginkan oleh organisasi dengan inputan data yaitu data kesehatan, proses dan output yaitu informasi pasien dan rekam medis pasien. Tahapan ini menjabarkan aplikasi-aplikasi yang telah ada dalam rumah sakit tersebut. Dari analisa pengamatan yang dilakukan dengan mensurvey rumah sakit maka untuk sistem yang saat ini umumnya ada dalam rumah sakit tersebut adalah website informasi rumah sakit, sistem rekam medis, 
sistem kasir, sistem apoteker dan sistem pelayanan antrian.

\section{Architecture Vision Phase}

Tahapan pada architecture vision ini digunakan untuk menggambarkan visi dan misi organisasi, dalam penelitian ini penggambaran visi dan misi dengan memberikan bagan yang dapat menggambarkan struktur dari usulan organisasi nantinya pada saat pengembangan.

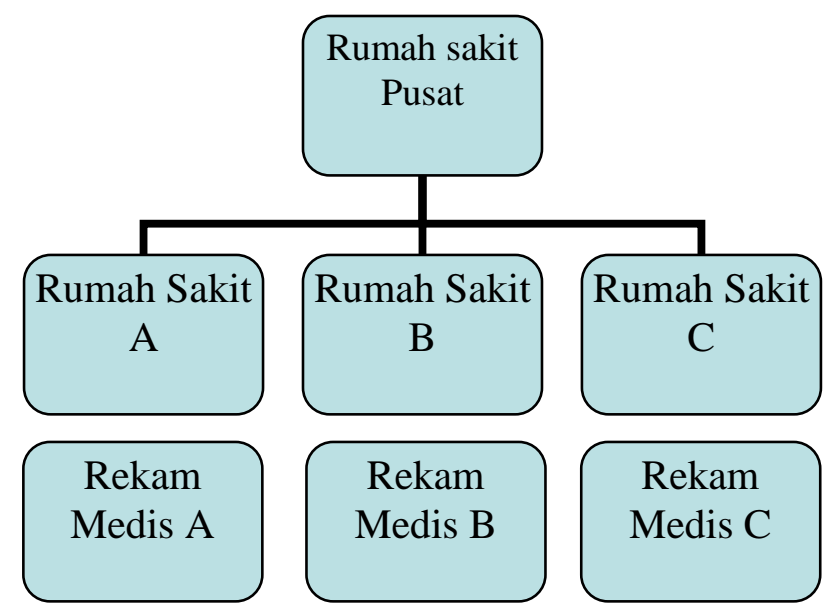

Gambar 2. Struktur Organisasi Rumah Sakit

Bagan diatas menggambarkan konsep yang diusulkan pada saat pengembangan strategi untuk meningkatkan pelayanan kesehatan pasien. Konsep utama dengan mengintegrasikan sebuah data yaitu rekam medis pasien agar dapat terlihat di rumah sakit lainnya dengan tujuan untuk mengetahui riwayat pasien tanpa mendata kembali kondisi kesehatan dan riwayat penyakit pasien. Dalam konsep terintegrasi ini dibutuhkan suatu pemahaman dan penentuan konsep yang bisa dijadikan acuan dalam pengambilan ataupun penginputan data rekam medis.

Berdasarkan hasil analisa diatas maka digambarakan sebuah value chain yang digunakan untuk memberikan contoh analisa aktifitas utama dan aktifitas pendukung dalam pelayanan kesehatan. Ada pun gambaran aktifitas utama dan aktifitas pendukung ini adalah sebagai berikut:

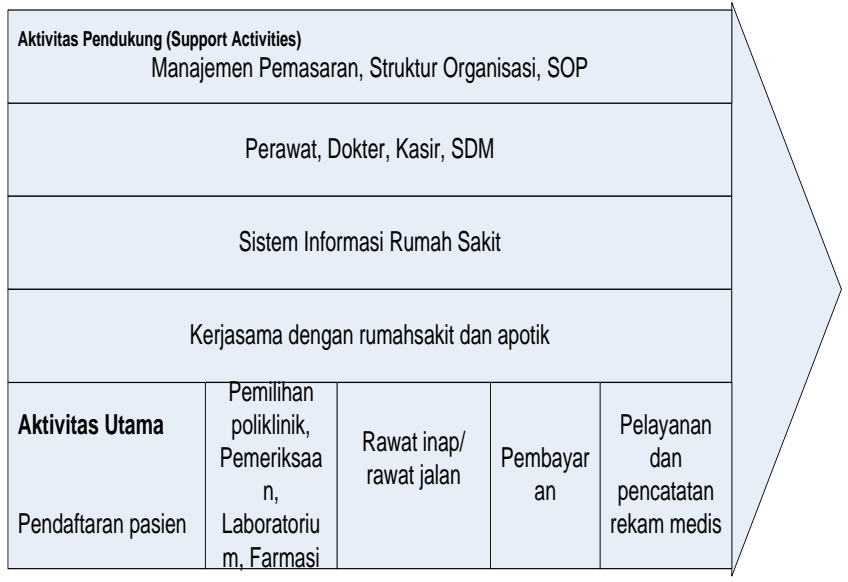

Gambar 3. Bagan Akftifitas

Aktifitas utama:

1. Pendaftaran pasien

2. Pemilihan poliklinik, pemeriksaan pasien, laboratorium dan farmasi.

3. Rawat inap/ rawat jalan

4. Pembayaran

5. Pelayanan rekam medis dan konsultasi kesehatan

Aktifitas pendukung dalam proses ini yang dapat digunakan untuk mendukung aktifitas kegiatan pelayanan kesehatan adalah:

1. Manajemen pemasaran, Struktur organisasi, SOP

2. Perawat,Dokter, Kasir, SDM

3. SIM RS

4. Kerjasama dengan rumah sakit lainnya serta apotik

Dari analisis value chain diatas menjelaskan bahwa dalam proses binsis rumah sakit diperlukan pendukung untuk dapat menjalakna kegiatan pelayanan rumah sakit. Aktifitas utama di laksanakan mulai dari input atau inbound logistic dan service dari kegiatan pelayanan kesehatan.

\section{Business Architecture}

Konsep bisnis pada pelayanan kesehatan yang menjadi permasalhan dalam penelitian ini adalah penerimaan pasien rawat inap sampai dengan rawat jalan dan pemilihan poliklinik untuk kesehatan serta perawatan dan konsultasi tentang kesehatan. Bisnis yang terjadi dalam proses kegiatan pelayanan ini 
merupakan proses secara umum yang telah dietapkan dalam SOP dan ketentuang di masing-masing rumah sakit. Dari analisis proses bisnis tersebut dilakukan pemetaan untuk mengetahui peluang dari bisnis kegiatan yang telah berjalan. Dalam proses pemetaan akan dilakukan analisa dengan SWOT untuk melihat bagaimana kondisi internal dan kondisi ekternal dengan memberikan gambaran bisnis dan peluang yang ada.

Tabel 1. Matriks SWOT

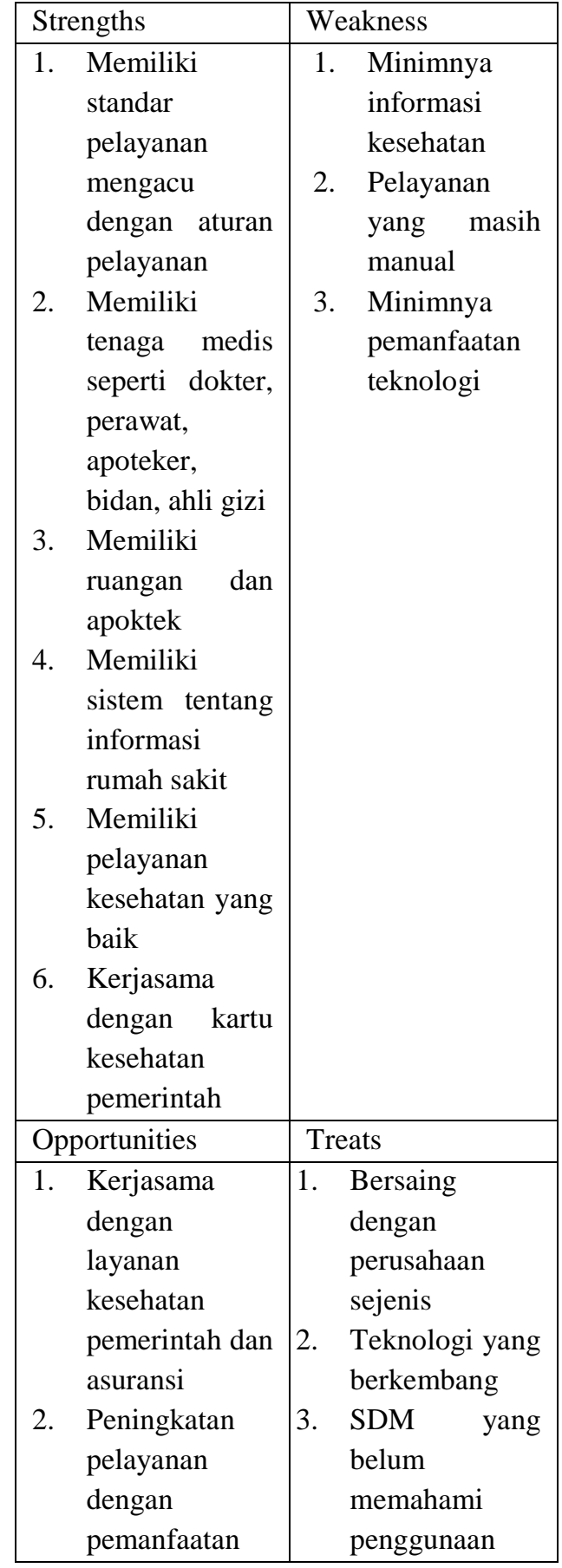

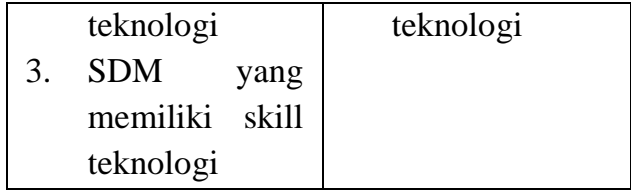

Tabel diatas menggambarkan pemetaan analisa dari sisi lingkungan internal dan lingkungan eksternal rumah sakit dengan membagi menjadi 4 faktor yaitu : kekuatan, kelemahan, peluang, serta ancaman. Pengelompokna dilakukan dengan menganalisa proses bisnis yang ada dan mengelompokan ke masing-masing faktor. Dari analisa yang telah dimasukan kedalam kelompok faktor tersebut maka akan dilakukan perhitungan dengan menyebarkan kusioner untuk menilai faktor mana yang mendapatkan hasil yang cukup tinggi untuk dapat menjadi gambaran dalam pengembangan perencanaan strategi pelayanan rumah sakit. Penyebaran kuisioner dilakukan ke 10 responden yang menjadi objek dalam penelitian ini.

Perhitungan Matriks Swot

Tabel 2 Strength

\begin{tabular}{|r|l|c|r|}
\hline NO & INDIKATOR & JUMLAH & BOBOT \\
\hline 1 & $\begin{array}{l}\text { Memiliki standar } \\
\text { pelayanan mengacu } \\
\text { dengan aturan } \\
\text { pelayanan }\end{array}$ & 40 & 4 \\
\hline 2 & $\begin{array}{l}\text { Memiliki tenaga } \\
\text { medis seperti dokter, } \\
\text { perawat, apoteker, } \\
\text { bidan, ahli gizi }\end{array}$ & 42 & 4.2 \\
\hline 3 & $\begin{array}{l}\text { Memiliki ruangan } \\
\text { dan apoktek }\end{array}$ & 46 \\
\hline 4 & $\begin{array}{l}\text { Memiliki sistem } \\
\text { tentang informasi } \\
\text { rumah sakit }\end{array}$ & 42 & 4.2 \\
\hline 5 & $\begin{array}{l}\text { Memiliki pelayanan } \\
\text { kesehatan yang baik }\end{array}$ & 44 & 4.4 \\
\hline 6 & $\begin{array}{l}\text { Kerjasama dengan } \\
\text { kartu kesehatan } \\
\text { pemerintah }\end{array}$ & 40 & 4.2 \\
\hline \multicolumn{2}{|c|}{ Rata-rata bobot } \\
\hline
\end{tabular}

Hasil dari penyebaran kusioner untuk kekuatan sebesar 4.2 yang artinya 
memiliki nilai yang cukup tinggi untuk melakukan pengembangan sistem dilihat dari kondisi yang telah berjalan dan teknologi yang ada.

Tabel 3. Weakness

\begin{tabular}{|r|l|c|r|}
\hline NO & INDIKATOR & JUMLAH & BOBOT \\
\hline 1 & $\begin{array}{l}\text { Minimnya informasi } \\
\text { kesehatan }\end{array}$ & 44 & 4.4 \\
\hline 2 & $\begin{array}{l}\text { Pelayanan yang masih } \\
\text { manual }\end{array}$ & 46 & 4.6 \\
\hline 3 & $\begin{array}{l}\text { Minimnya } \\
\text { pemanfaatan teknologi }\end{array}$ & 42 & 4.2 \\
\hline \multicolumn{2}{|c|}{ Rata-rata bobot } \\
\hline
\end{tabular}

Tabel diatas merupakan kelemahan yang dapat diterima oleh pengembang sistem dengan skor 4.4, dimana proses bisnis memiliki poin yang cukup tinggi dengan kelemahan yang ada. Sehingga jika terjadi perencanaan dalam pengembangan sistem memiliki peluang yang cukup besar untuk memperbaiki proses kerja dan bisnis perusahaan.

\section{Tabel 4. Opportunities}

\begin{tabular}{|r|l|c|r|}
\hline NO & INDIKATOR & JUMLAH & BOBOT \\
\hline 1 & $\begin{array}{l}\text { Kerjasama dengan } \\
\text { layanan kesehatan } \\
\text { pemerintah dan } \\
\text { asuransi }\end{array}$ & 44 & 4.4 \\
\hline 2 & $\begin{array}{l}\text { Peningkatan } \\
\text { pelayanan dengan } \\
\text { pemanfaatan } \\
\text { teknologi }\end{array}$ & 48 & 4.8 \\
\hline 3 & $\begin{array}{l}\text { SDM yang } \\
\text { memiliki skill } \\
\text { teknologi }\end{array}$ & 48 & 4.8 \\
\hline \multicolumn{2}{|c|}{ Rata-rata bobot } & 4.7 \\
\hline
\end{tabular}

Tabel diatas menjelaskan peluang yang bisa dilakukan oleh perusahaan untuk dapat melakukan pengembangan terhadap sistem informasi yang ada, dengan hasil kuisioner sebesar 4.7 memberikan gambaran bahwa peluang yang di dapat oleh perusahaan cukup tinggi untuk dapat melakukan pengembangan strategi informasi.
Tabel 5. Threat

\begin{tabular}{|r|l|c|r|}
\hline NO & INDIKATOR & JUMLAH & BOBOT \\
\hline 1 & $\begin{array}{l}\text { Bersaing dengan } \\
\text { perusahaan sejenis }\end{array}$ & 40 & 4 \\
\hline 2 & $\begin{array}{l}\text { Teknologi yang } \\
\text { berkembang }\end{array}$ & 40 & 4 \\
\hline 3 & $\begin{array}{l}\text { SDM yang belum } \\
\text { memahami } \\
\text { penggunaan } \\
\text { teknologi }\end{array}$ & 48 & 4.8 \\
\hline \multicolumn{2}{|c|}{ Rata-rata bobot } & 4.3 \\
\hline
\end{tabular}

Tabel diatas menggambarkan ancaman yang terjadi dan sangat besar nilai yang dicapai. Dari nilai tersebut berarti sebuah perusahaan memilikiancaman yang cukup besar dalam melaksanakan proses pelayanan kesehatan. Skor yang dicapai yaitu 4.3 menunjukan nilai yang cukup tinggi untuk dapat melakukan proses pengembangan sistem.

Dari hasil kuisioner dalam penelitian ini memberikan hasil dari masing-masing skor dimana peluang dalam perencanaan strategi untuk mengembangkan sistem ini cukup tinggi melihat kondisi teknologi yang ada dengan ancaman yang cukup besar maka akan dilakukan sebuah perencanaan strategi pengembangan sistem dalam pelayanan kesehatan di rumah sakit. Pengembangan pelayanan dengan melihat faktor teknologi dan persaingan yang ada dalam kondisi saat ini. 


\section{Architecture Technologi}

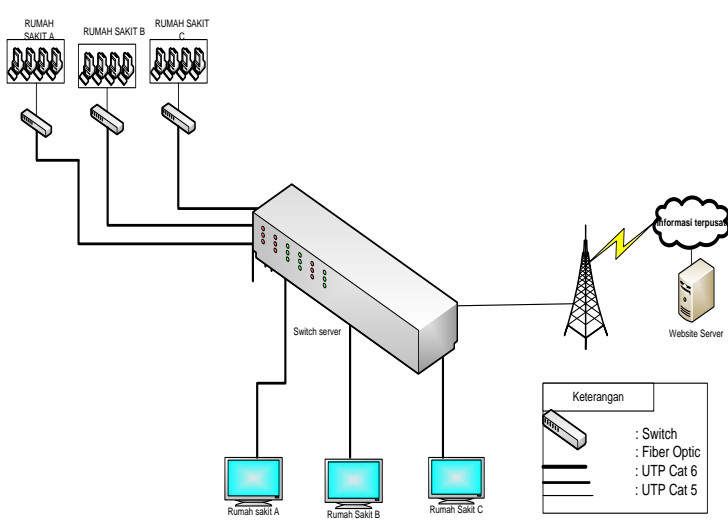

Gambar 4. Infrastruktur Teknologi

Gambaran ini merupakan usulan infrastruktur teknologi yang akan dikembangkan dalam perencanaan pelayanan kesehatan. Usulan infrastruktur nya dengan merancang 1 buah sistem terpusat dengan mengintegrasikan dengan rumah sakit A sampai dengan rumah sakit $\mathrm{C}$ yang nantinya data rekam medis jika akan digunakan di rumah sakit berbeda dapat terlihat oleh rumah sakit tersebut. Tujuan nya agar pada saat pasien akan melakukan perpindahan rumah sakit data pasien tercatat dan dapat digunakan oleh rumah sakit tanpa harus merekam kembali data yang ada.

\section{SIMPULAN}

Penelitian yang telah dilakukan memberikan hasil bahwa telah tergambar suatu usulan pengembangan sistem informasi dengan usulan infrastruktur teknologi yang ada dan dari hasil kusioner yang telah dilakukan memberikan kesimpulan bahwa kekuatan yang dimiliki cukup rendah namun peluang dan ancaman memiliki skor yang tinggi. Dimana kekuatan rumah sakit sebesar 4.2 dan peluang memiliki skor 4.7 serta ancaman memiliki skor 4.3. Maka dari hasil kuisioner tersebut memberikan gambaran dan hasil bahwa kegiatan dapat dilakukan dengan merencanakan strategi pengembangan sistem dan merekomendasikan usulan teknologi yang akan dibangun

\section{DAFTAR PUSTAKA}

[1]. Subowo.Moh Hadi., 2016., Perancangan Infrastruktur Teknologi Informasi Adaptif Menggunakan Kerangka Kerja TOGAF ADM dan SONA., Jakarta.,Karya Akhir

[2]. Chaudhry, B., Wang, J., \& Wu, S. (2006). Systematic review: impact of health information technology on quality, efficiency, and costs of medical care,.Annals of Internal Medicine, vol. 144, no. 10, pp. 742-752.

[3]. The Open Group. (2011). TOGAF® Version 9.1 Enterprise Edition. U.S: The Open Group.

[4]. Nugroho.Hendrianto

A.,Darwiyanto.Eko.,Agung.Gede., Perencanaan Strategis Sistem Informasi Rumah Sakit Kusuma Ungaran dengan Metode Anita Cassidy.,2017., eproceeding of enginerring: $\mathrm{Vol} 4$, No 1 April 2017 